\title{
MGIT DICCH RỬA NộI SOI PHẾ QUẢN PHẾ NANG CHẨN ĐOÁN LAO PHỔI AFB ÂM TẠI THÁI NGUYÊN
}

\section{TÓM TẮT}

Mục tiêu: Xác định và so sánh các giá trị của MGIT, Xpert và ZN dịch rửa nội soi phế quản phế nang chẩn đoán lao phổi. Đối tượng và phương pháp: Nghiên cứu mô tả tai Bênh viên Lao và bệnh Phổi Thái Nguyên, từ 1/2020-12/2020. Thu nhận 90 bênh nhân nghi lao, AFB âm hoăc ít đờm, nôi soi rửa phế quản phế nang làm MGIT, Xpert và ZN. Kết quả: Xét nghiêm MGIT so với tiêu chuẩn kết hợp chẩn đoán lao có độ nhạy là $72,5 \%$, độ đặc hiệu $71,4 \%$, giá trị dự đoán dương tính $89,3 \%$ và giá trị dự đoán âm tính $44,1 \%$. Xét nghiệm MGIT so với tiêu chuẩn Xpert chẩn đoán lao cóđố nhay là $64,3 \%$, đô đăc hiêu $82,4 \%$, giá trị dự đoán dương tính $85,7 \%$ và giá trị dự đoán âm tính $58,3 \%$. Kết luân: Xét nghiệm MGIT dich rửa nôi soi phế quản phế nang chẩn đoán lao phổi hiệu quả hơn ZN ở bênh nhân nghi lao, AFB âm và ít đờm.

Tư khóa: Lao phổi, AFB âm, MGIT, Xpert, ZN.

\section{SUMMARY}

\section{MGIT BRONCHOSCOPIC BRONCHOSCOPIC} LAVAGE FOR THE DIAGNOSIS IN SPUTUMSMEAR NEGATIVE PULMONARY TUBERCULOSIS

Objectives: Evaluationand compare values of MGIT, Xpert and ZN for bronchoscopy bronchoscopic lavage for the diagnosisin sputum-smear negative pulmonary tuberculosis. Subjects and methods: Descriptive study at Thai Nguyen Tuberculosis and Lung Disease Hospital, from 1 / 2020-12 / 2020. There were 90 patients with suspected tuberculosisin sputum-smear negative or less sputum. MGIT, Xpert and $\mathrm{ZN}$ of bronchoscopy bronchoscopic lavage. Results: MGIT assay against the standard with combined TB diagnosis had a sensitivity of $72.5 \%$, a specificity of $71.4 \%$, a positive predictive value of $89.3 \%$ and a negative predictive value $44,1 \%$. The MGIT test against the Xpert standard for TB diagnosis had a sensitivity of $64.3 \%$, a specificity of $82.4 \%$, a positive predictive value of $85.7 \%$ and a negative predictive value of $58.3 \%$. Conclusions: Bronchoalveolar bronchial lavage MGIT test were more effective in diagnosing pulmonary tuberculosis than $\mathrm{ZN}$ in patients with suspected $\mathrm{TB}$, in sputumsmear negative and less sputum.

Key words: Pulmonary tuberculosis, sputumsmear negative, MGIT, Xpert, ZN.

\section{I. ĐẶT VẤN ĐỀ}

Hiện nay, bệnh lao vẫn là một vấn đề sức

*Trường Đại họ Y Dược Thái Nguyên

Chịu trách nhiệm chính: Hoàng Hà

Email: hoangha@tnmc.edu.vn

Ngày nhận bài: 2/3/2021

Ngày phản biên khoa học 25/3/2021

Ngày duyệt bài: 9/4/2021

\section{Hoàng Hà*, Ngô Thị Hoài*}

khỏe toàn cầu có số bệnh nhân tử vong xếp hàng thứ 9 trên thế giới và đứng đâu trong các bênh có nguyên nhân do một loại nhiễm khuẩn, đứng trên cả HIV/AIDS. Năm 2019 thế giới có 6,3 triệu lao mới; có 10,4 triệu người bị mắc lao và 1,3 triệu người tử vong do lao. Việt Nam đứng thứ 13 trong số 30 nước có số người bệnh lao cao trên thế giới [5]. Phát hiện lao bằng soi đờm trực tiếp là phương pháp thường dùng để chẩn đoán lao phổi, nhưng khó tìm thấy AFB trong trường hợp số lượng vi khuẩn lao ít, bệnh nhân ít đờm. Nội soi lấy dịch rửa phế quản phế nang nuôi cấy MGIT hữu ích trong chẩn đoán lao phổi AFB âm [2-4]. Nghiên cứu MGIT dịch rửa phế quản phế nang tại Thái Nguyên còn mới và có ít đề tài. Chúng tôi tiến hành nghiên cứu này nhằm các mục tiêu sau:

- Xác định giá trị MGIT dịch rửa nội soi phế quản phế nang trong chẩn đoán lao phổi.

- So sánh giá trị MGIT, Xpert và ZN dịch rứa nọi soi phế quản phế nang trong chẩn đoán lao phôii.

\section{II. ĐỐI TƯợNG VÀ PHƯƠNG PHÁP NGHIÊN CứU}

2.1. Đối tượng, thời gian và địa điểm nghiên cứu: Nghiên cứu tiến hành tại Bệnh viện Lao và bênh Phổi (L\&BP) Thái Nguyên, từ 1/2020-12/2020. Tiêu chuẩn chọn bệnh nhân từ 18 tuổi trở lên, được chẩn đoán lao phổi AFB (-) [1], theo dõi điêuu trị 6 tháng. Tiêu chuẩn loại là những bệnh nhân không đủ điều kiện nội soi.

2.2. Phương pháp nghiên cứu: Nghiên cứu mô tả, thiết kế cắt ngang, cõ mẫu toàn bộ.Nghiên cứu thu nhận các bệnh nhân đủ tiêu chí về nghi lao, khan hiếm đờm, hội chẩn chuyên khoa lao, theo dõi, giám sát, đánh giá điều trị 60 ngày, sau cùng chẩn đoán xác định có 69 bệnh nhân lao phổi và 21 bênh nhân bềnh phổi ngoài lao.

\subsection{Chỉ tiêu nghiên cứu}

- Về các đặc điểm cơ bản và lâm sàng xét nghiệm của bệnh nhân

- Giá trị và so sánh các giá trị MGIT, Xpert, ZN dịch rửa phế quản phế nang

2.4. Tiêu chuẩn, kỹ thuật trong nghiên cứu

Nội soi phế quản: Bệnh nhân được nội soi phế quản bằng sợi quang mềm đượcrửa phế quản phế nang dựa trên kết quả chụp Xquang và quyết định của kỹ thuật viên, lấy $5 \mathrm{ml}$ làm các xét nghiệm. Lấy $1 \mathrm{ml}$ dịch rửa cho làm Xpert, số dịch còn lại được xử lý theo quy trình khử khuẩn, ly 
tâm nhuộm Ziehl-Neelsen và nuôi cấy trên hệ thống BACTEC mycobacterium growth tube (MGIT) 960.

Chẩn đoán lao phổi: Cách thứ nhất lấytiêu chuẩn chẩn đoán lao phổi AFB (-) [1]và có theo dõi điều trị bao gồm: có lâm sàng nghi lao, Xquang có tổn thương, soi đờm AFB $(-)$, hai tuần kháng sinh ngoài lao không kết quả, hội chẩn hoặc một trong các xét nghiện Xpert mtb/rif, MGIT và $Z N$ dương tính, hoặc người bệnh đáp ứng tốtvới việc điều trị thuốc lao,theo dõi6 tháng. Các trường hợp còn lạicó chẩn đoán thay thế là các bệnh phổi ngoài lao. Cách thứ hai chọn kết quả Xpert dịch rửa phế quản phế nang dương tính là tiêu chuẩn vàng chẩn đoán lao phổi [4].

Chẩn đoán bệnh phổi ngoài lao: dựa vào các tiêu chuẩn của riêng từng bệnh phổi do bác sỹ chuyên khoa xác định như: viêm phổi, giãn phế quản, ung thư phổi.

2.5. Phương pháp thu thập xử lí số liệu: Thông tin cơ bản về nhân khẩu học, lâm sàng, Xquang, nội soi và các xét nghiệm được ghi vào bệnh án nghiên cứu. Số liệu thu thậpđược nhập vàophân tích thống kê trền SPSS. Độ nhạy, độ đặc hiệu và các giá trị dự đoán, khoảng tin cậy $95 \%$, so sánh các giá trị được tính trên Epi Open. Giá trị $p<0,05$ được là có ý nghĩa thống kê.

2.6. Đạo đức nghiên cứu: Nghiên cứu được phê duyệt bởi Hội đồng Đạo đức Trường ĐH Y Dược và Ban Lãnh đạo Bệnh viện L\&BP
Thái Nguyên. Bệnh nhân đều tự nguyện tham gia bằng văn bản, được giải thích đây đủ quy trình cần thực hiện trong nghiên cứu.

\section{KẾT QUẢ NGHIÊN CỨU}

Bảng 1. Đặc điểm của bệnh nhân nghi lao soi đờn $A F B(-)$ và ít đờm

\begin{tabular}{|c|c|c|c|}
\hline \multicolumn{2}{|c|}{ Nhóm tuổi } & \multirow{2}{*}{$\begin{array}{c}\begin{array}{c}\text { Số lượng } \\
\text { (n=90) }\end{array} \\
47,8 \pm \\
17,2 \\
\end{array}$} & \multirow{2}{*}{\begin{tabular}{|c|}
$\begin{array}{c}\text { Tỷ lệ } \\
(\mathbf{\%})\end{array}$ \\
Min=19, \\
Max=89 \\
\end{tabular}} \\
\hline \multicolumn{2}{|c|}{ Tuổi trung bình } & & \\
\hline \multirow{2}{*}{ Giới } & Nam & 50 & 55,6 \\
\hline & Nữ & 40 & 44,4 \\
\hline \multirow{2}{*}{$\begin{array}{l}\text { Soi đờm } \\
\text { tìm AFB }\end{array}$} & Ãm tính & 73 & 81,1 \\
\hline & Không có đờm & 17 & 18,9 \\
\hline \multirow{5}{*}{$\begin{array}{l}\text { Lâm } \\
\text { sàng }\end{array}$} & $\mathrm{Ho}$ & 72 & 82,2 \\
\hline & Ho ra máu & 8 & 8,9 \\
\hline & Khó thở & 28 & 31,1 \\
\hline & Đau ngực & 30 & 33,3 \\
\hline & Gây sút cân & 14 & 15,6 \\
\hline \multirow{5}{*}{$X$ quang } & Nốt & 25 & 27,8 \\
\hline & Đám mờ & 64 & 71,1 \\
\hline & Hang & 11 & 12,2 \\
\hline & Tốn thương đỉnh & 32 & 35,6 \\
\hline & Hạch trung thất & 5 & 0,56 \\
\hline
\end{tabular}

Nhận xét: Chênh lệch tỷ lệ nam nữ là $55,6 \%$ so với $44,4 \%$. Tuổi trung bình là $47,8 \pm 17,2$. Số có ít đờm chiếm đáng kể là $18,9 \%$. Triệu chứng ho và đau ngực chiếm cao nhất là $82,2 \%$ và $33,3 \%$. Tổng thương đám mờ trên $X$ quang cao nhất là $71,1 \%$.

Bảng 2. Giá trị các xét nghiệm dịch rửa phế quản phếnang

\begin{tabular}{|c|c|c|c|c|c|}
\hline \multicolumn{2}{|c|}{$\begin{array}{l}\text { Giá trị } \\
\text { Xétnghiêm dich rửa }\end{array}$} & $\begin{array}{c}\text { Độ nhạy } \\
\% \text { (CI 95\%) }\end{array}$ & $\begin{array}{l}\text { Độ đặc hiệu } \\
\text { (sp) }\end{array}$ & $\begin{array}{l}\text { Giá trị dự báo } \\
\text { dương (PPV) }\end{array}$ & $\begin{array}{l}\text { Giá trị dự báo } \\
\text { âm (NPV) }\end{array}$ \\
\hline \multirow{3}{*}{$\begin{array}{l}\text { So với kết } \\
\text { hợp chẩn } \\
\text { đoán }\end{array}$} & Xpert & $72,5(54,4-94,7)$ & $71,4(41,5-100,0)$ & $89,3(67,0-100,0)$ & $44,1(25,6-71,1)$ \\
\hline & MGIT & $55,1(39,5-74,8)$ & $81,0(48,7-100,0)$ & $90,5(65,0-100,0)$ & $35,4(21,3-55,6)$ \\
\hline & ZN & $21,7(12,6-35,1)$ & $76,2(45,1-100,0)$ & $, 6-100,0)$ & $22,9(13,5-36,3)$ \\
\hline \multirow{2}{*}{$\begin{array}{c}\text { So với } \\
\text { Xpert }\end{array}$} & MGIT & $64,3(45,7-88,0)$ & $82,4(55,8-100,0)$ & $0,0)$ & $58,3(39,5-83,1)$ \\
\hline & $\mathrm{ZN}$ & $26,8(15,6-43,2)$ & $85,3(58,2-100,0)$ & $75,0(43,6-100,0)$ & $41,4(28,3-58,7)$ \\
\hline
\end{tabular}

Nhận xét: Xét nghiệm MGIT so với tiêu chuấn kết hợp chẩn đoán lao cóđộ nhạy là $55,1 \%(39,5 \%$ - 74,8\%), độđặc hiệu $81,0 \%(48,7 \%-100,0 \%)$, giá trị dự đoán dương tính 90,5\% $(65,0 \%-100,0 \%)$ và giá trị dự đoán âm tính $35,4 \%(21,3 \%-55,6 \%)$. Xét nghiệm MGIT so với tiêu chuẩn Xpert chẩn đoán lao cóđộ nhạy là $64,3 \%(45,7 \%-88,0 \%)$, độđặc hiệu 82,4\% $(55,8 \%-100,0 \%)$, giá trị dự đoán dương tính $85,7 \%(61,0 \%-100,0 \%)$, và giá trị dự đoán âm tính $58,3 \%(39,5 \%-83,1 \%)$.

Bảng 3. So sánh giá trị của Xpert với MGIT và ZNtheo chẩn đoán kêt hợp

\begin{tabular}{|c|c|c|c|c|}
\hline Xét nghiệm Giá trị & $\begin{array}{l}\text { Độ nhạy } \\
\text { (se) }\end{array}$ & $x 2, p$ & $\begin{array}{l}\text { Độ đặc hiệu } \\
\text { (sp) }\end{array}$ & $x^{2}, p$ \\
\hline Xpert & 72,5 & \multirow{2}{*}{$1,0,>0,05$} & 71,4 & \multirow{2}{*}{$0,07, p>0,05$} \\
\hline MGIT & 55,1 & & 81,0 & \\
\hline Xpert & 72,5 & \multirow{2}{*}{$13,2, p<0,01$} & 71,4 & \multirow{2}{*}{$0,02, p>0,05$} \\
\hline $\mathrm{ZN}$ & 21,7 & & 76,2 & \\
\hline
\end{tabular}

Nhận xét: Theo chuấn chấn đoán kết hợp, xét nghiệm Xpert có độ nhạy và độ đặc hiệu cao hơn xét nghiệm MGIT và ZN, trong đó có độ nhạy $(72,5 \%)$ cao hởn rõ rệt so với ZN $(21,7 \%)$ có ý nghĩa thống kê. 
Bảng 4. So sánh các giá trị của MGIT và ZNtheo từng tiêu chuẩn vàng

\begin{tabular}{|c|c|c|c|c|c|}
\hline \multicolumn{2}{|c|}{ Tiêu chuẩn và $X N \quad$ Giá trị } & $\begin{array}{l}\text { Độ nhạy } \\
\text { (se) }\end{array}$ & $x^{2}, p$ & $\begin{array}{c}\text { Độ đặc } \\
\text { hiệu (sp) }\end{array}$ & $x^{2}, p$ \\
\hline \multirow{2}{*}{$\begin{array}{c}\text { So với kết hợp } \\
\text { chẩn đoán }\end{array}$} & MGIT & 55,1 & \multirow{2}{*}{$7,3,<0,01$} & 81,0 & \multirow{2}{*}{$0,02, p>0,05$} \\
\hline & $\mathrm{ZN}$ & 21,7 & & 76,2 & \\
\hline So với Xpert & $\frac{\text { MGIT }}{\text { ZN }}$ & $\begin{array}{l}64,3 \\
26,8\end{array}$ & $6,0, p<0,01$ & $\begin{array}{l}82,4 \\
85,3\end{array}$ & $0,01, p>0,05$ \\
\hline
\end{tabular}

Nhận xét: Xét nghiêm MGIT có độ nhay cao hơn có ý nghĩa thống kê so với xét nghiệm ZN, ở cả tiêu chuẩn kết hợp chẩn đoán và so với Xpert. Độ đặc hiệu của MGIT và ZN là tương đương nhau trong khoảng trên dưới 80,0\%, khác biệt không có ý nghĩa thống kê.

\section{BÀN LUẬN}

4.1. Một số đặc điểm cơ bản của bệnh nhân nghiên cứu. Bệnh nhân nam $(55,6 \%)$ nhiều hơn nữ $(44,4 \%)$, nhưng không chênh nhiều như trong những bệnh lao phổi. Tuổi trung bình $47,8 \pm 17,2$ là tuổi cũng hay gặp nhất ở bênh nhân lao [5]. Số có ít đờm chiếm đáng kể là $18,9 \%$. Các triệu chứng ho, đau ngực, Xquang phổi có hình mờ gặp khá cao là cũng hay gặp ở bệnh nhân lao phối nói chung [5].

Có $73(81,1 \%)$ bênh nhân đều có AFB (-) dù đã nhiều lần nhuộn ZNN soi đờm trực tiếp cho thây nhóm bệnh nhân này rất khó có chẩn đoán sớm. Có $17(18,9 \%)$ bệnh nhân khan hiếm đờm, nên không thể chẩn đoán được lao theo lấy đờm tự nhiên mà phải lấy dịch rửa phế quản phế nang.

4.2 Giá trị của các xét nghiệm MGIT dịch rửa phế quản phế nang chẩn đoán lao. Khi lấy tiêu chuẩn vàng là "kết hợp chẩn đoán", MGIT cóđộ nhạy là 55,1\% (95\% 39,5\% $74,8 \%)$, độđđặc hiệu $81,0 \%(48,7 \%-100,0 \%)$, giá trị dự đoán dương tính 90,5\% (65,0\% $100,0 \%)$ và giá trị dự đoán âm tính $35,4 \%$ $(21,3 \%-55,6 \%)$. Khi lấy tiêu chuẩn vàng làXpert, MGIT cóđộ nhạy là $64,3 \%(45,7 \%$ $88,0 \%)$, độđặc hiệu $82,4 \%(55,8 \%-100,0 \%)$, giá trị dự đoán dương tính $85,7 \%(61,0 \%-$ $100,0 \%)$, và giá trị dự đoán âm tính $58,3 \%$ $(39,5 \%-83,1 \%)$. Các kết quả này so với nghiên cứu của Disha Bhatia và Nikhil C Gowda[2, 3] có độ nhạy là $50,0 \%$ là thấp hơn, độđặc hiệu $100,0 \%$, giá trị dự đoán dương tính $100,0 \%$ và giá trị dự đoán âm tính $98,2 \%$ lại cao hơn.Kết quả các giá trị khác nhau do nhiêu nguyên nhân, do thành thục khi lấy dịch rửa phế quản phế nang, do thuốc gây tê Xylocainecó thể cản trở sự phát triển của vi khuẩn lao, do vị trí lấy dịch rửa.

4.2. So sánh MGIT với Xpert và ZN. Theo tiêu chuẩn kết hợp chẩn đoán, xét nghiệm Xpert có độ nhạy và độ đặc hiệu cao hơn xét nghiệm MGIT và ZN, trong đó có độ nhạy $(72,5 \%)$ cao hơn rõ rệt so với ZN $(21,7 \%)$ có ý nghĩa thống kê. Xét nghiệm MGIT có độ nhạy cao hơn có ý nghĩa thống kê so với xét nghiệm ZN, ở cả tiêu chuẩn kết hợp chẩn đoán và Xpert. Độ đặc hiệu của MGIT và $Z N$ là tương đương khoảng trển dưới $80,0 \%, p>0,05$.

Theo tiêu chuẩn kết hợp chẩn đoán, với thời gian dài tới 6 tháng làm số lượng bệnh nhân nghiên cứu được chẩn đoán lao tăng thêm 31 trường hợp ngoài kết quả từ MGIT và 54 trường hợp ngoài kết quả của ZN. Tương tự, theo tiêu chuẩn Xpert chẩn đoán, số lượng bệnh nhân nghiên cứu được chẩn đoán lao tăng thêm lần lượt là 20 với MGIT và 41 với ZN. Khi đó sẽ làm thay đổi các giá trị xét nghiệm của MGIT và ZN dịch rửa phế quản phế nang.

Cùng loại bệnh phẩm là dịch rửa phế quản phế nang, độ nhạy chẩn đoán lao của MGIT luôn cao hơn ZN, đó là căn cứ tin cậy để thầy thuốc lâm sàng chỉ định xét nghiệm MGIT chẩn đoán những thể nghi lao AFB âm và ít đờm.

\section{KẾT LUÂN}

Xét nghiệm MGIT chẩn đoán lao phổi hiệu quả hơn tìm $\mathrm{AFB}$ bằng $\mathrm{ZN}$ ở dịch rửa nội soi phế quản phế nang trong những bệnh nhân nghi lao AFB âm và ít đờm. Xét nghiệm MGIT so với tiêu chuẩn kết hợp chẩn đoán lao cóđộ nhạy là $72,5 \%$, độ đặc hiệu $71,4 \%$, giá trị dự đoán dương tính $89,3 \%$ và giá trị dự đoán ầm tính $44,1 \%$. Xét nghiệm MGIT so với tiêu chuẩn Xpert chẩn đoán lao cóđộ nhạy là $64,3 \%$, độđặc hiệu $82,4 \%$, giá trị dự đoán dương tính $85,7 \%$ và giá trị dự đoán âm tính 58,3\%.

\section{TÀI LIÊU THAM KHẢO}

1. Bộ Y tế, (2018), Hướng dẫn chẩn đoán, điều trị vâ dự phòng bệnh lao, Quyết định số 3126/QĐ BYT, $\operatorname{Tr} 1-3$.

2. Disha Bhatia, et al, (2021), Evaluation and comparison of molecular and conventional diagnostic modalities for detecting pulmonary tuberculosis in bronchoalveolar lavage fluid,Indian Journal of Medical Microbiology Volume 39, Issue 1 , pp 48-53.

3. Nikhil C Gowda, et al, (2018), Evaluation of Xpert $\AA$ Mycobacterium tuberculosis/rifampin in sputum-smear negative and sputum-scarce patients with pulmonary tuberculosis using 
bronchoalveolar lavage fluid, Lung India. 35(4): 295-300.

4. Yanjun Lu, et al, (2018) Evaluating the diagnostic accuracy of the Xpert MTB/RIF assay on bronchoalveolar lavage fluid: A retrospective study, International Journal of Infectious Diseases 71, pp 14-19.

5. World Health Organization, (2019), Global tuberculosis report 2019,ISBN 978-92-4-156571-4, pp 1-7, $27-68$.

\section{YẾU TỐ ẢNH HƯỞNG ĐẾN KHẢ NĂNG CHI TRẢ CHO GÓI KHÁM TƯ VẤN VÀ PHÁT HIẾN SỚM UNG THƯ VÚ TẠI KHOA TẦM SOÁT UNG THƯ, BÊ̂NH VIỆN UNG BƯỚU THÀNH PHỐ HỒ CHÍ MINH NĂM 2019}

Nguyễn Quỳnh Anh*

\section{TÓM TẮT}

Mục tiêu: Nghiên cứu được thực hiện nhằm tìm hiểu một số yếu tố ảnh hưởng đến khả năng chi trả cho gói khám tư vấn và phát hiện sớm ung thư vú tại Khoa Tầm soát Ung thư, Bệnh viện Ung bướu Thành phố Hồ Chí Minh năm 2019. Phương pháp nghiên cứu: Nghiên cứu cắt ngang sử dụng số liệu định lượng (thu thập từ phát vấn với 240 phụ nữ) và số liệu định tính (tổ chức 2 cuộc thảo luận nhóm với 14 phụ nữ đến đăng ký khám tại Khoa Tâm soát ung thư') trong thời gian từ tháng $04 / 2019$ đến tháng 9/2019. Kết quả và kết luận: Mỗt số yếu tố ảnh hưởng đến việc lựa chọn cũng như sẵn sàng chi trả để sử dụng gói khám TSUT bao gồm bị tác động từ gia đình, người than, thu nhập của bản thân/gia đình; giá của gói dịch vụ được niêm yết; uy tín của cơ sở y tế và tính chất bệnh. Bên cạnh đó, có sự khác biệt giữa khả năng chi trả của phụ nữ với các nhóm nghề nghiệp, trong đó nhóm nhân viên văn phòng có khả năng chi trả cao hơn các nhóm nghề nghiệp còn lai; có sư khác biệt giữa khả năng chi trả của phụ nữ với thu nhập trung bình của toàn bô gia đình, trong đó thu nhập trung bình từ 30 triệu trở lên có khả nẳng chi trả cao hơn các mức thu nhập còn lại.

Từ khoá: khả năng chi trả, yếu tố ảnh hưởng, khám tầm soát ung thư, ung thư vú, bệnh viện Ung bướu

\section{SUMMARY}

SEVERAL INFLUENCING FACTORS ON ABILITY TO PAY OF AN ON-SERVICE BREAST CANCER COUNSELING AND EARLY

DETECTION PACKAGE AT HO CHI MINH CITY ONCOLOGY HOSPITAL, 2019

Objective: The study was conducted to understand some influencing factors on the ability to pay of an on-service breast cancer counseling and early detection packages at the Department of Cancer Screening, Ho Chi Minh City Oncology Hospital in 2019. Methods: Cross-sectional study using

*Trường Đại học Y tế Công Cộng

Chịu trách nhiệm chính: Nguyễn Quỳnh Anh

Email: nqa@huph.edu.vn

Ngày nhận bài: 22.2.2021

Ngày phản biên khoa học: 29.3.2021

Ngày duyệt bài: 5.4.2021 quantitative data collected from interviewing with 240 women and group discussion with 14 women registered at the Department of Cancer Screening between April 2019 and September 2019. Results and conclusions: A number of factors influencing the choice of as well as the willingness to pay to use the early detection package include family impacts, coalitioners, self/family income; the listedprice of the service package; reputation of hospital and the nature of the disease. In addition, there is a difference between women's affordability and occupational groups, in which office workers are more likely to pay than the rest of the occupation groups. There is also a difference between women's ability to pay and the average income of the whole family, with an average income of 30 million or more being more affordable than the rest of the income groups.

Keywords: ability to pay, counseling and early detection packages, breast cancer, Ho Chi Minh City Oncology Hospital

\section{I. ĐĂT VẤN ĐỀ}

Năm 2018, theo thống kê của Cơ quan quốc tế nghiên cứu về ung thư GLOBOCAN tại Việt Nam, tổng số ca măc mới ung thư nhiêu nhất thuộc về ung thư gan (23.335 trường hợp), tiếp đến là ung thư phổi (23.667 trường hợp), ung thư dạ dày (17.527 trường hợp) tiếp theo là ung thư đại trực tràng (14.272 trường hợp) và ung thư vú (15.229 trường hợp)(1). Ung thư vú (UTV) là bệnh ung thư hay gặp nhất ở phụ nữ và là nguyên nhân gây tử vong cao tại các nước trên thế giới. Tại Việt Nam, theo nghiên cứu gánh nặng bệnh ung thư và chiến lược phòng chống ung thư quốc gia đến năm 2020 cho thấy UTV là bệnh có tỷ lệ mới mắc cao nhất trong các ung thư ở nữ giới (2). Mặc dù tỷ lệ mắc UTV có xu hướng tăng trong những năm gần đây nhưng tỷ lệ tử vong do bệnh vẫn từng bước được cải thiện nhờ các thành tựu đạt được trong phòng bệnh, phát hiện bệnh sớm, chẩn đoán và điêu trị. Việc tâm soát ung thư sẽ giúp người dân phát hiện bệnh sớm, tăng khả năng điêu trị thành cồng, giảm quá tải cho hệ thống y tế khi phải điều trị cho bệnh nhân ở giai đoạn bệnh 